\title{
Short-term regulation of insulin-mediated glucose utilization in four-day fasted human volunteers: role of amino acid availability
}

\author{
P.J.Flakoll ${ }^{1}$, L.S. Wentzel ${ }^{1}$, D. E. Rice ${ }^{1}$, J.O. Hill ${ }^{3}$ and N. N. Abumrad ${ }^{1,2,4}$ \\ Departments of ${ }^{1}$ Surgery, ${ }^{2}$ Medicine, ${ }^{3}$ Pediatrics and \\ ${ }^{4}$ Molecular Physiology and Biophysics Vanderbilt University Medical Center Nashville, Tennessee, USA
}

\begin{abstract}
Summary. Glucose homeostasis in men fasted for $84 \mathrm{~h}$ was assessed using isotopes, indirect calorimetry and forearm balance techniques during a basal period and three sequential hyperinsulinaemic euglycaemic clamps each lasting for $150 \mathrm{~min}$. Two protocols ( $n=12$ in each) were used: subjects were either allowed to develop hypoaminoacidaemia or received a commercial solution of L-amino acids while maintaining near-basal plasma leucine levels. Insulin infusions resulted in 3-,35- and 650-fold increases in plasma insulin levels in both protocols. The infusion of amino acids produced a rightward shift in the dose-response curve of insulin's effect on suppressing hepatic glucose production, indicating decreased sensitivity in addition to blunting of the maximal responsiveness. Total body glucose rate of disappearance was progressively increased with escalating insulin doses, but was $22 \%$ lower at the intermediate and highest insulin doses in
\end{abstract}

the group that was infused with amino acids $(3.44 \pm 0.53 \mathrm{vs}$ $4.82 \pm 0.71$ and $7.72 \pm 1.01$ vs $10.36 \pm 1.08 \mathrm{mg} \cdot \mathrm{kg}^{-1} \cdot \mathrm{min}^{-1}$, respectively; $p<0.05$ ). Forearm balance data confirmed the isotopic data, since amino acid infusions blunted the insulinmediated increase in net forearm glucose utilization (by 50 $83 \%$ ). Furthermore, the infusion of amino acids resulted in marked reductions in the rate of carbohydrate oxidation and storage as assessed by indirect calorimetry. The data indicate that the amino acid-mediated suppression of glucose utilization and carbohydrate oxidation is exerted on the responsive component of insulin action.

Key words: Insulin responsiveness, insulin sensitivity, glucose utilization, glucose production, hyperinsulinaemic euglycaemic clamp.
Extended fasting and uncontrolled diabetes are characterized by alterations in glucose regulatory hormones, elevated non-esterified fatty acids, increased plasma amino acids and increased resistance to insulin-mediated glucose utilization. The cause of this insulin resistance has been the focus of considerable research aimed at improving treatment of diabetes, post-surgical trauma and infection-related stress. Elevated plasma non-esterified fatty acids have been shown to decrease glucose utilization and as a result have been implicated as a major factor contributing to increased insulin resistance [1]. Additionally, the increases in circulating levels of plasma cortisol [2], epinephrine [3], growth hormone [4] and glucagon [5], singly or in combination, have been demonstrated to enhance resistance to insulin-mediated glucose disposal.

The role that the elevated levels of amino acids play in modulating insulin's action on glucose homeostasis during fasting is not well defined. Several studies have indicated that high protein diets promoted glucose intolerance in rats [6-9] and humans [10-12]. A previous study from our laboratory [13] and another by Tessari et al. [14] have es- tablished that during repeated insulin clamps in overnight fasted volunteers, the amount of exogenous glucose infused to maintain euglycaemia was considerably less when amino acids were simultaneously given to maintain near euaminoacidaemia. Unfortunately, in our study, glucose kinetics were not assessed, and hence we were unable to dissect the effects of amino acid infusions on the various components of glucose metabolism, i.e. on the rates of glucose production and utilization and on carbohydrate storage and oxidation.

Using an amino acid clamp recently developed in our laboratory [15], in combination with indirect calorimetry, glucose tracer technology and forearm balance, we examined the importance of preventing the development of hypoaminoacidaemia on the dose-responsive effects of insulin on various aspects of glucose and carbohydrate metabolism in $84 \mathrm{~h}$-fasted human volunteers. In this manner, we established the effect of amino acids on tissue sensitivity and responsiveness to the action of insulin on glucose production and disposal and on carbohydrate oxidation in a group of individuals fasted for $84 \mathrm{~h}$. It is well es- 

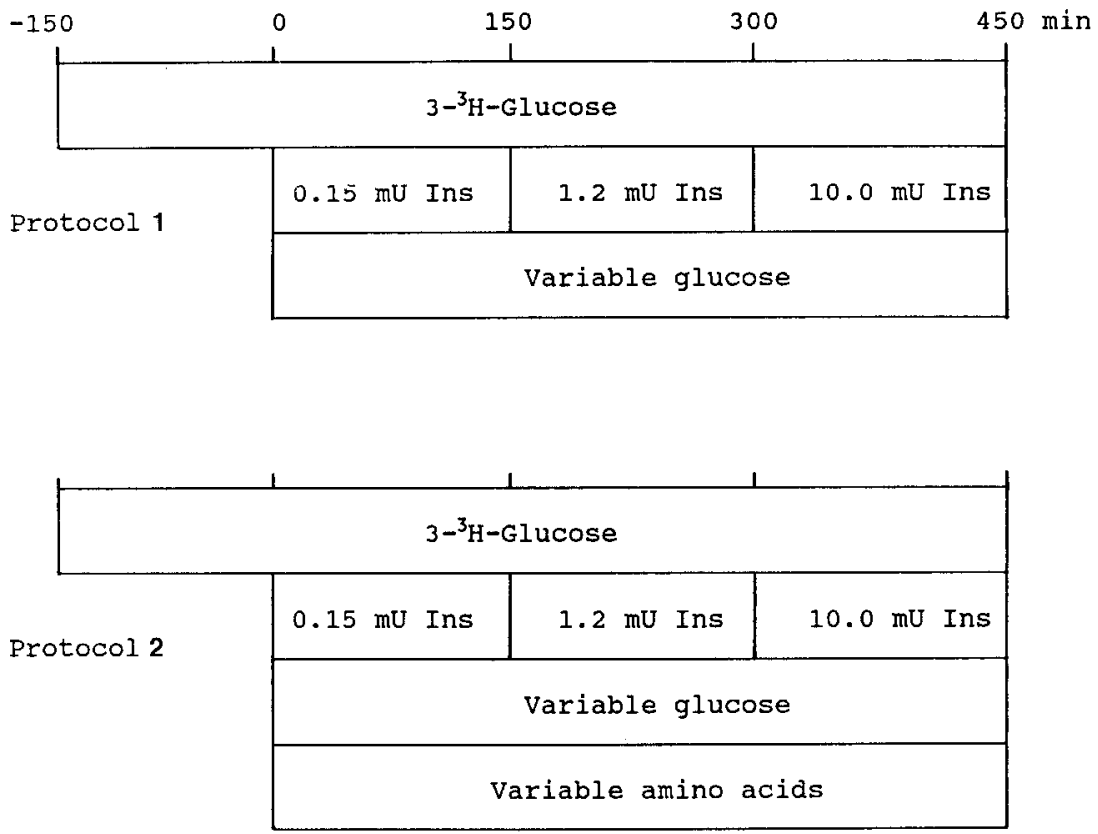

Fig. 1. Experimental protocols. Each study consisted of a 150-min equilibration period during which only $\left[3-{ }^{3} \mathrm{H}\right]$ glucose was infused and a $450-$ min experimental period during which insulin (Ins) was infused at progressively increasing doses $\left(0.15,1.2\right.$ and $10.0 \mathrm{mU} \cdot \mathrm{kg}^{-1} \cdot \mathrm{min}^{-1}$, respectively). Exogenous infusion of glucose was used to maintain euglycaemia. During the experimental period in Protocol 1, plasma amino acids were allowed to fall, whereas in Protocol 2, an exogenous infusion of a commercially available L-amino acid solution was employed to maintain basal plasma amino acid concentrations tablished that 4-day fasting is associated with a state of insulin resistance, with significant alterations in plasma amino acid levels and with depleted stores of glycogen both in the liver and muscle, conditions which are similar to those associated with stress. Hence, the present study will attempt to examine whether the changes in plasma amino acids seen during fasting contribute to the insulin resistance associated with fasting.

\section{Subjects, materials and methods}

\section{Human subjects}

Studies were carried out in 12 normal male volunteers (aged 18 to 45 years) who were within $10 \%$ of their ideal body weight and BMI (Metropolitan Life Insurance Company Tables of 1959). All subjects had a normal glucose tolerance test. None of the subjects had any evidence, by history or physical examination, of diabetes mellitus, or of cardiac, liver, pulmonary or renal diseases. All studies were performed in the Clinical Research Center and the protocols were approved by the Committee for the Protection of Human Subjects of the Institutional Review Board at Vanderbilt University. Written consent was obtained from each subject. All subjects were placed on a balanced weight-maintenance diet for at least 1 week prior to the day of the study.

All subjects participated in two studies, which were 3 weeks apart. In each study, euglycaemia was maintained during three sequential insulin infusions. In one study, hypoaminoacidaemia was allowed to develop and in another hypoaminoacidaemia was prevented by the exogenous infusion of an L-amino acid solution. The order of the studies was randomized. All subjects were studied following an 84-h fast, during which they were allowed to carry out their normal activities and to consume water ad libitum.

Oxidation of substrates was determined by open circuit calorimetry [16] on the morning of each day of the fast, and on the day of the experiment during a $30 \mathrm{~min}$ basal period and during the last $30 \mathrm{~min}$ of each insulin infusion period. During these periods, each subject breathed into a transparent mask connected to a Sensor Medics (Palo Alto, Calif., USA) 2900 metabolic cart for the determination of ventilation rates, $\mathrm{CO}_{2}$ production and $\mathrm{O}_{2}$ consumption. The oxidative rates of leucine were determined using the primed con- tinuous infusion of $\mathrm{L}-\left[{ }^{14} \mathrm{C}\right]$ leucine in a group of subjects fasted for the same time period and subjected to the same experimental design. The kinetic data for this group of subjects were previously reported from this laboratory [17].

On the morning of the study (06.30-07.00 hours), an 18-gauge angiocatheter was placed in a superficial vein of the non-dominant arm for blood sampling and the hand was heated to $55^{\circ} \mathrm{C}$ to ensure complete arterialization [18]. In addition, a 16-gauge angiocatheter was inserted into a forearm vein of the dominant arm and threaded to the subclavian vein for the infusion of insulin, $20 \%$ dextrose in water, $\left[3-{ }^{3} \mathrm{H}\right]$ glucose, L-amino acids and potassium phosphate, as required. In five subjects, an additional catheter was threaded retrograde into a brachial vein of the dominant arm and used for blood sampling.

Capacitance plethysmography was used to measure forearm blood flow [19]. For this procedure, two capacitance cuffs were placed tightly around the forearm of the dominant extremity. The capacitance across the forearm is converted to a change in voltage by a capacitance plethysmography (model 2560, Biochem/NC, Culver City, Calif., USA) while the venous return to the arm is occluded by inflating the cuff to $60 \mathrm{~mm} \mathrm{Hg}$. The change in voltage is transferred to a recorder (Millipore, Millford, Mass., USA) and compared with a voltage change induced by a standard volume. Flow to the hand was interrupted $2 \mathrm{~min}$ before and during blood collection by a blood pressure cuff placed at the wrist and inflated to $100 \mathrm{~mm} \mathrm{Hg}$ above systolic blood pressure. Blood flow and arteriovenous measurements were obtained in five subjects.

\section{Experimental design (Fig. 1)}

Each study consisted of a $120 \mathrm{~min}$ tracer equilibration period $(-150$ to $-30 \mathrm{~min}$ ), a $30 \mathrm{~min}$ basal period ( -30 to $0 \mathrm{~min}$ ) and a $450 \mathrm{~min} \mathrm{ex}-$ perimental period ( 0 to $450 \mathrm{~min}$ ). Starting at $\mathrm{t}=-150 \mathrm{~min}$ each subject received a bolus $(20 \mu \mathrm{Ci}$ over $2 \mathrm{~min}$ ) injection followed by a continuous $(0.2 \mu \mathrm{Ci} / \mathrm{min})$ infusion of HPLC-purified $\left[3-{ }^{3} \mathrm{H}\right]$ glucose (New England Nuclear, Boston, Mass., USA) as previously described [20] to assess whole-body glucose kinetics. At $t=0 \mathrm{~min}$, subjects were given sequential infusions of insulin at $0.15,1.2$ and $10.0 \mathrm{mU} \cdot \mathrm{kg}^{-1} \cdot \mathrm{min}^{-1}$, each lasting for $150 \mathrm{~min}$. Regular human insulin (Squibb-Novo Inc., Princeton, N.J., USA) was diluted to the proper concentration with $0.9 \% \mathrm{NaCl}$ containing the subject's own plasma $(3.0 \%$, volume/volume, $v / v)$ and potassium phosphate 
Table 1. Arterial glucose, insulin and glucagon concentrations

\begin{tabular}{lcccc}
\hline $\begin{array}{l}\text { Rate of insulin } \\
\text { infused } \\
\mathrm{mU} \cdot \mathrm{kg}^{-1} \cdot \mathrm{min}^{-1}\end{array}$ & $\begin{array}{l}\text { Plasma } \\
\text { glucose } \\
\mathrm{mmol} / \mathrm{l}\end{array}$ & $\begin{array}{l}\text { Plasma } \\
\mathrm{NEFA} \\
\mu \mathrm{mol} / \mathrm{L}\end{array}$ & $\begin{array}{l}\text { Plasma } \\
\text { insulin } \\
\mu \mathrm{U} / \mathrm{ml}\end{array}$ & $\begin{array}{l}\text { Plasma } \\
\mathrm{glucagon} \\
\mathrm{pg} / \mathrm{ml}\end{array}$ \\
\hline AA & & & & \\
Basal & $3.8 \pm 0.1$ & $1254 \pm 239$ & $4 \pm 1$ & $172 \pm 11$ \\
0.15 & $4.4 \pm 0.1$ & $659 \pm 67$ & $13 \pm 2$ & $119 \pm 15^{\mathrm{a}}$ \\
1.2 & $4.0 \pm 0.2$ & $254 \pm 77$ & $155 \pm 28$ & $93 \pm 19^{\mathrm{a}}$ \\
10.0 & $3.9 \pm 0.2$ & $61 \pm 15$ & $2558 \pm 493$ & $64 \pm 12^{\mathrm{a}}$ \\
$+\mathrm{AA}$ & & & & \\
Basal & $3.6 \pm 0.1$ & $1120 \pm 156$ & $4 \pm 1$ & $177 \pm 18$ \\
0.15 & $4.0 \pm 0.2$ & $642 \pm 59$ & $15 \pm 3$ & $172 \pm 28^{\mathrm{b}}$ \\
1.2 & $3.6 \pm 0.1$ & $346 \pm 87$ & $128 \pm 19$ & $267 \pm 32^{\mathrm{a}, \mathrm{b}}$ \\
10.0 & $3.5 \pm 0.2$ & $92 \pm 47$ & $2829 \pm 515$ & $297 \pm 56^{\mathrm{a}, \mathrm{b}}$ \\
\hline
\end{tabular}

The values represent mean \pm SEM of four determinations per subject during a $30 \mathrm{~min}$ basal period or the last $30 \mathrm{~min}$ of each insulin infusion period. NEFA, non-esterified fatty acids. ${ }^{a}$ denotes significance from basal mean at $p<0.05$. ${ }^{b}$ denotes significance from corresponding value in Protocol $1, p<0.05$. - AA designates Protocol 1 in which plasma amino acids were allowed to fall, + AA designates Protocol 2 in which amino acids were infused

(0.13 mEq/ml; LyphoMed Inc., Melrose Park, Ill., USA). In addition, during each insulin infusion, euglycaemia was maintained by monitoring plasma glucose every $5-10 \mathrm{~min}$ and by administering variable exogenous glucose infusions $(20 \%$ dextrose in water, $\mathrm{Ab}-$ bott Laboratories, North Chicago, Ill., USA) as previously described [21]. During the $30 \mathrm{~min}$ basal period and the last $30 \mathrm{~min}$ of each experimental period, continuous open circuit indirect calorimetry was performed.

Each subject was studied twice. In Protocol 1, plasma amino acids were allowed to fall in response to hyperinsulinaemia, whereas in Protocol 2 plasma leucine was maintained near basal levels. This was achieved by frequent monitoring (every $10-15 \mathrm{~min}$ ) of plasma leucine [15] and, using a negative feedback algorithm, by exogenous infusion of an L-amino acid solution. The commercial amino acid solution used ( $8.5 \%$ Travesol, Travenol Laboratories, Deerfield, Ill., USA) contained in $\mathrm{mg} / 100 \mathrm{ml}$ : leucine 526 , lysine 492 , phenylalanine 526 , isoleucine 406 , valine 390 , histidine 372 , threonine 356 , tryptophan 152 , alanine 1760 , glycine 1760 , arginine 880 , proline 356 and tyrosine 34 .

\section{Biochemical analyses}

Blood samples were obtained from the heated superficial hand vein at $10 \mathrm{~min}$ intervals during the basal period ( -30 to $0 \mathrm{~min}$ ) and during the last $30 \mathrm{~min}$ of each insulin infusion period. Blood was collected in heparinized syringes, transferred to tubes containing $\mathrm{Na}_{2}$ EDTA $(15 \mathrm{mg} /$ tube $)$ and centrifuged. The plasma obtained was immediately placed on ice. Aliquots were used for immediate assay of glucose by the glucose oxidase method (Glucose II analyser, Beckman Instruments, Fullerton, Calif., USA) and for plasma leucine by HPLC [15]. Plasma glucose radioactivity was determined by liquid scintillation counting after precipitation of plasma protein with barium hydroxide and zinc sulphate (1:4.5:4.5, v/v/v), drying the supernatant and reconstitution in $1 \mathrm{ml}$ of water and $10 \mathrm{ml}$ of scintillation fluid (Ecolite ${ }^{(-)}$, ICN Biomedicals Inc., Irvine, Calif., USA). The remainder of the plasma was frozen at $-20^{\circ} \mathrm{C}$ for later assay of individual amino acids, non-esterified fatty acids, insulin, cortisol and glucagon. Plasma amino acids were analysed on PITC-derivatized plasma using HPLC [22]. Plasma non-esterified fatty acids were analysed enzymatically (Wako Chemicals USA Inc, Richmond, Va., USA). Immunoreactive insulin was measured using the sephadex-bound antibody procedure [23]. Immunoreactive glucagon was measured in plasma samples (containing $50 \mu \mathrm{l}$ of 500,000 units/ml aprotinin, Trasylol, FBA Pharmaceutical, New York, N. Y., USA) by radioimmunoassay using the 30 kilodalton antiserum of Unger [24], which was obtained from the University of Texas, Southwestern Medical School (Dallas, Tex., USA). Standard glucagon and ${ }^{125}$ I-glucagon were obtained from Novo Research Institute (Copenhagen, Denmark).

\section{Calculations}

Rates of glucose production ( $\mathrm{Ra}$ ) and utilization ( $\mathrm{Rd}$ ) were calculated from the dilution of the steady-state specific activities of $\left[{ }^{3} \mathrm{H}\right]$ glucose in plasma as previously described [25]. The rate of endogenous glucose production (endogenous $\mathrm{Ra}$ ) was calculated by subtracting the rate of exogenous glucose infusion from the total glucose Ra. Recently, there have been several reports of the above tracer method underestimating glucose production during hyperinsulinaemic euglycaemic clamp studies [26-28]. Therefore, in the present studies, when glucose infusion rates were greater than total glucose $\mathrm{Ra}$, the resulting negative values were treated as such.

Rates of substrate oxidation were calculated using a combination of indirect calorimetry data with isotopically-derived data for amino acid oxidation. Rates of amino acid oxidation were derived from a group of subjects who were of similar body weight and age, who had fasted for the same period of time and who were subjected to the same experimental design described herein [17]. After subtracting the calories of amino acids oxidized from the total calorie expenditure, the rates of lipid and carbohydrate oxidation were then determined from the non-protein respiratory quotient [29]. Limitations and assumptions of using indirect calorimetry to calculate substrate oxidation have been previously addressed [16]. Carbohydrate storage was calculated as the difference between the rates of glucose utilization and carbohydrate oxidation.

Forearm flow $\left(\mathrm{ml} \cdot 100 \mathrm{ml}^{-1}\right.$ forearm muscle $\left.\cdot \mathrm{min}-1\right)$ was estimated by dividing the rate of bloodflow by the forearm volume. The rate of blood flow was estimated by the voltage deflection across the forearm in response to venous occlusion. Forearm volume was estimated from the volume of a cone encompassed by the capacitance cuffs. Forearm plasma flow was calculated by dividing blood flow by (1-haematocrit). Net glucose uptake was calculated as the product of arteriovenous differences and forearm plasma flow.

\section{Statistical analysis}

All values are expressed as the mean \pm SEM. The data were analysed with a two-way repeated-measures analysis of variance to test treatment effects. When significance $(p<0.05)$ was established, the difference between the individual means was determined post-hoc with Newman-Keuls Test [30].

\section{Results}

Plasma glucose, non-esterified fatty acids, insulin and glucagon concentrations

Basal plasma levels of insulin, non-esterified fatty acids and glucagon after the $84 \mathrm{~h}$ fast were identical in the two protocols, as shown in Table 1. Within $90 \mathrm{~min}$ of the start of each hyperinsulinaemic euglycaemic clamp, new steady-state plasma insulin levels were achieved. The levels attained in both protocols were identical and averaged approximately 3-, 35- and 650-fold basal levels with sequential insulin infusions of $0.15,1.2$ and $10.0 \mathrm{mU}$. $\mathrm{kg}^{-1} \cdot \min ^{-1}$, respectively. Plasma glucose levels were maintained near basal and did not differ between the two protocols.

Hyperinsulinaemia, in the presence of euglycaemia and hypoaminoacidaemia (Protocol 1), resulted in pro- 
Table 2. Arterial amino acid concentrations

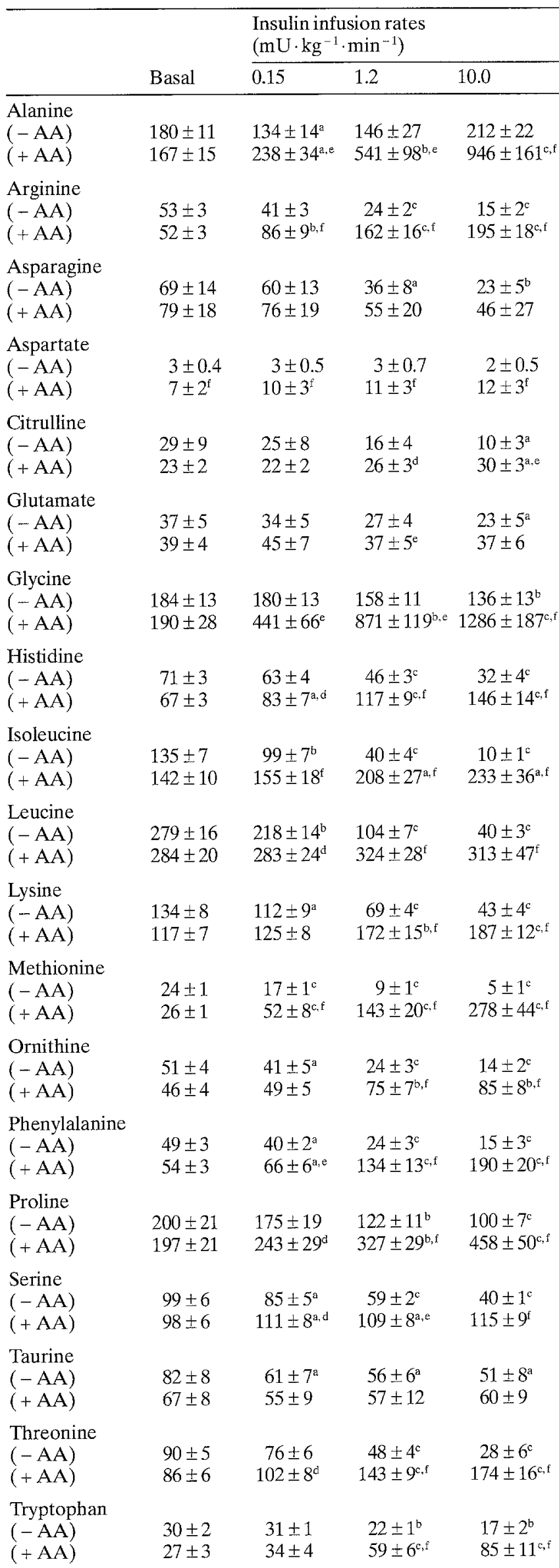

Table 2 (continued). Arterial amino acid concentrations

\begin{tabular}{|c|c|c|c|c|}
\hline & \multirow[b]{2}{*}{ Basal } & \multicolumn{3}{|c|}{$\begin{array}{l}\text { Insulin infusion rates } \\
\left(\mathrm{mU} \cdot \mathrm{kg}^{-1} \cdot \mathrm{min}^{-1}\right)\end{array}$} \\
\hline & & 0.15 & 1.2 & 10.0 \\
\hline $\begin{array}{l}\text { Tyrosine } \\
(-\mathrm{AA}) \\
(+\mathrm{AA})\end{array}$ & $\begin{array}{l}47 \pm 2 \\
51 \pm 3\end{array}$ & $\begin{array}{l}34 \pm 2^{\mathrm{b}} \\
42 \pm 3^{\mathrm{a}, \mathrm{d}}\end{array}$ & $\begin{array}{l}18 \pm 1^{\mathrm{c}} \\
41 \pm 4^{\mathrm{a}, \mathrm{f}}\end{array}$ & $\begin{array}{l}10 \pm 1^{\mathrm{c}} \\
59 \pm 11^{\mathrm{f}}\end{array}$ \\
\hline $\begin{array}{l}\text { Valine } \\
(-\mathrm{AA}) \\
(+\mathrm{AA})\end{array}$ & $\begin{array}{l}369 \pm 24 \\
396 \pm 24\end{array}$ & $\begin{array}{l}316 \pm 22 \\
396 \pm 33^{\mathrm{e}}\end{array}$ & $\begin{array}{l}187 \pm 13^{\mathrm{c}} \\
486 \pm 37^{\mathrm{a}, \mathrm{f}}\end{array}$ & $\begin{array}{c}95 \pm 8^{\mathrm{c}} \\
547 \pm 64^{\mathrm{a}, \mathrm{f}}\end{array}$ \\
\hline $\begin{array}{l}\text { Total } \\
(-\mathrm{AA}) \\
(+\mathrm{AA})\end{array}$ & $\begin{array}{l}2214 \pm 89 \\
2279 \pm 138\end{array}$ & $\begin{array}{l}1844 \pm 95^{\mathrm{a}} \\
2762 \pm 259^{\mathrm{e}}\end{array}$ & $\begin{array}{l}1237 \pm 30^{\mathrm{c}} \\
4141 \pm 373^{\mathrm{b}}\end{array}$ & $\begin{array}{c}921 \pm 37^{\mathrm{c}} \\
5520 \pm 624^{\mathrm{c}, \mathrm{f}}\end{array}$ \\
\hline $\begin{array}{l}\text { Essential } \\
(-\mathrm{AA}) \\
(+\mathrm{AA})\end{array}$ & $\begin{array}{l}1292 \pm 58 \\
1300 \pm 58\end{array}$ & $\begin{array}{l}1042 \pm 56^{b} \\
1452 \pm 119^{\mathrm{e}}\end{array}$ & $\begin{array}{c}651 \pm 26^{\mathrm{c}} \\
2211 \pm 170^{\mathrm{c}}\end{array}$ & $\begin{array}{c}466 \pm 28^{c} \\
2956 \pm 310^{c, i}\end{array}$ \\
\hline $\begin{array}{l}\text { Non-essential } \\
(-\mathrm{AA}) \\
(+\mathrm{AA})\end{array}$ & $\begin{array}{l}923 \pm 39 \\
979 \pm 104\end{array}$ & $\begin{array}{c}801 \pm 45^{\mathrm{a}} \\
1311 \pm 152^{\mathrm{e}}\end{array}$ & $\begin{array}{c}587 \pm 20^{\mathrm{c}} \\
1930 \pm 218^{\mathrm{b}}\end{array}$ & $\begin{array}{c}455 \pm 17^{c} \\
\text { off } 2565 \pm 331^{\mathrm{b}, \mathrm{f}}\end{array}$ \\
\hline $\begin{array}{l}\text { Branched-chai } \\
(-\mathrm{AA}) \\
(+\mathrm{AA})\end{array}$ & $\begin{array}{c}\text { amino acids } \\
783 \pm 46 \\
822 \pm 52\end{array}$ & $\begin{array}{l}630 \pm 42^{\mathrm{a}} \\
834 \pm 74^{\mathrm{d}}\end{array}$ & $\begin{array}{c}331 \pm 24^{\mathrm{c}} \\
1018 \pm 89^{\mathrm{a}, \mathrm{f}}\end{array}$ & $\begin{array}{c}146 \pm 11^{\mathrm{c}} \\
1094 \pm 146^{\mathrm{a}, \mathrm{f}}\end{array}$ \\
\hline
\end{tabular}

The values are expressed in $\mu \mathrm{mol} / 1$. - AA designates Protocol 1 in which plasma amino acids were allowed to fall. + AA designates Protocol 2 in which amino acids were infused. ${ }^{a, b}$ and ${ }^{c}$ denote significance from basal values at $p<0.05, p<0.01$ and $p<0.001$, respectively; ${ }^{\text {dee }}$ and ${ }^{\mathrm{f}}$ denote differences between $-\mathrm{AA}$ and $+\mathrm{AA}$ at $p<0.05, p<0.01$ and $p<0.001$, respectively

gressive decrements in plasma glucagon reaching approximately $60 \%$ basal levels at the highest insulin dose infused. When amino acids were infused (Protocol 2), the drop in plasma glucagon was blunted at each insulin dose used. With the lowest insulin dose, plasma glucagon remained near basal, but the level increased $51 \%$ and $68 \%$ above basal with the intermediate and highest insulin doses, respectively. At the highest insulin dose used, the plasma glucagon levels attained in Protocol 2 were nearly 4.5-fold those achieved in Protocol $1(p<0.001)$.

Plasma non-esterified fatty acid levels averaged $1187 \pm 198 \mu \mathrm{mol} / \mathrm{l}$ after $84 \mathrm{~h}$ of fasting. These levels decreased with increasing insulin infusion rates, but did not differ between the two protocols. The infusion of insulin or amino acids did not alter circulating plasma cortisol or catecholamine levels (data not shown).

\section{Plasma amino acids}

Fasting for $84 \mathrm{~h}$ was associated with significant $(p<0.01)$ increases in the plasma levels of the three branched chain amino acids; plasma leucine increased $124 \%$ (to $280 \pm$ $5 \mu \mathrm{mol} / \mathrm{l}$ ), isoleucine increased $138 \%$ (to $138 \pm 8 \mu \mathrm{mol} / \mathrm{l}$ ) and valine increased $71 \%$ (to $382 \pm 24 \mu \mathrm{mol} / 1$ ). Some amino acids declined such as alanine $(-62 \%$ to $174 \pm 13 \mu \mathrm{mol} / 1)$, threonine $(-47 \%$ to $88 \pm 5 \mu \mathrm{mol} / \mathrm{l})$, arginine $(-41 \%$ to $53 \pm 3 \mu \mathrm{mol} / \mathrm{l})$, lysine $(-24 \%$ to $125 \pm 7 \mu \mathrm{mol} / \mathrm{l})$ and glycine $(-22 \%$ to $231 \pm 52 \mu \mathrm{mol} / \mathrm{l})$. Plasma levels of histidine, methionine, ornithine, phenylalanine, serine, tryptophan and tyrosine did not change with fasting. 
Table 3. Rates of glucose infusion and whole-body rates of endogenous glucose appearance $(\mathrm{Ra})$ and disappearance $(\mathrm{Rd})$ during hyperinsulinaemic euglycaemic clamps

\begin{tabular}{llcc}
\hline $\begin{array}{l}\text { Rate of } \\
\text { insulin infusion } \\
\mathrm{mU} \cdot \mathrm{kg}^{-1} \cdot \mathrm{min}^{-1}\end{array}$ & $\begin{array}{l}\text { Rate of } \\
\text { glucose infusion } \\
\mathrm{mg} \cdot \mathrm{kg}^{-1} \cdot \mathrm{min}^{-1}\end{array}$ & $\begin{array}{l}\text { Glucose } \\
\text { total Rd } \\
\mathrm{mg} \cdot \mathrm{kg}^{-1} \cdot \mathrm{min}^{-1}\end{array}$ & $\begin{array}{l}\text { Glucose } \\
\text { endogenous Ra } \\
\mathrm{mg} \cdot \mathrm{kg}^{-1} \cdot \mathrm{min}^{-1}\end{array}$ \\
\hline - AA & & $1.43 \pm 0.10$ & $1.43 \pm 0.10$ \\
Basal & 0.00 & $1.74 \pm 0.27^{\mathrm{a}}$ & $0.68 \pm 0.34^{\mathrm{a}}$ \\
0.15 & $1.06 \pm 0.15$ & $4.82 \pm 0.71^{\mathrm{a}}$ & $0.54 \pm 0.45^{\mathrm{a}}$ \\
1.2 & $4.27 \pm 0.46$ & $10.36 \pm 1.08^{\mathrm{a}}$ & $-0.15 \pm 1.19$ \\
10.0 & $10.51 \pm 0.81$ & & \\
$+\mathrm{AA}$ & & $1.57 \pm 0.20$ & $1.57 \pm 0.20$ \\
Basal & 0.00 & $2.20 \pm 0.52^{\mathrm{a}}$ & $1.75 \pm 0.58^{\mathrm{b}}$ \\
0.15 & $0.45 \pm 0.08^{\mathrm{a}, \mathrm{b}}$ & $3.44 \pm 0.53^{\mathrm{a}, \mathrm{b}}$ & $1.53 \pm 0.31^{\mathrm{b}}$ \\
1.2 & $1.92 \pm 0.37^{\mathrm{a}, \mathrm{b}}$ & $3.472 \pm 1.01^{\mathrm{a}, \mathrm{b}}$ & $0.95 \pm 0.46$ \\
10.0 & $6.78 \pm 0.73^{\mathrm{a} . \mathrm{b}}$ & 7.72 & \\
\hline
\end{tabular}

a denotes significance from basal $(p<0.05)$ within the same proto$c o l .{ }^{b}$ denotes significance from corresponding period in Protocol 1 $(p<0.05)$. - AA designates Protocol 1 in which plasma amino acids were allowed to fall. + AA designates Protocol 2 in which amino acids were infused

Sequential infusions of insulin were associated with plasma leucine concentrations $22 \%, 63 \%$ and $86 \%$ below basal levels, respectively. Exogenous infusions of L-amino acids were sufficient to maintain plasma leucine levels near basal in Protocol 2. The rates of L-amino acids infused averaged $1.08 \pm 0.19,3.73 \pm 0.99$ and $4.73 \pm$ $1.02 \mathrm{mg} \cdot \mathrm{kg}^{-1} \cdot \mathrm{min}^{-1}$, respectively. These correspond to infusion rates of leucine of $0.51 \pm 0.09,1.76 \pm 0.47$ and $2.23 \pm 0.48 \mu \mathrm{mol} \cdot \mathrm{kg}^{-1} \cdot \mathrm{min}^{-1}$, respectively.

In Protocol 1, the levels of total plasma amino acids dropped progressively with sequential insulin infusions as shown in Table 2. As the dosage of insulin infused was increased, the plasma levels of total amino acids were reduced by $13 \%, 36 \%$ and $51 \%$, respectively. This reduction was due to a decrease in both essential amino acids $(-19 \%,-50 \%$ and $-64 \%$, respectively) and non-essential amino acids $(-13 \%,-36 \%$ and $-51 \%$, respectively). Plasma levels of the branched chain amino acids appeared to be particularly sensitive to insulin with the levels dropping $20 \%, 58 \%$ and $81 \%$, respectively; the drop in plasma isoleucine levels was the highest, while the drop in plasma valine was the lowest. In Protocol 2, despite maintaining plasma leucine near basal, hyperaminoacidaemia developed with increasing insulin dosages. The majority of the increase was accounted for by increases in the levels of the non-essential amino acids $(+22 \%,+81 \%$ and $+140 \%$, respectively). The most significant increases occurred with plasma glycine and alanine $(+466 \%,+356 \%$, respectively, at the highest insulin dose used), the two most abundant amino acids in the commercial solution infused.

\section{Glucose kinetics}

The amount of glucose infused to maintain euglycaemia increased progressively with escalating insulin infusions. However, at each dose of insulin used, the amount of exogenous glucose required to maintain euglycaemia was
$36-58 \%$ lower in the group where amino acids were infused. The rates of glucose infused averaged $0.45 \pm 0.08 \mathrm{vs}$ $1.1 \pm 0.2 \mathrm{mg} \cdot \mathrm{kg}^{-1} \cdot \mathrm{min}^{-1}$ for the lowest insulin dose, $1.9 \pm 0.4$ vs $4.3 \pm 0.5 \mathrm{mg} \cdot \mathrm{kg}^{-1} \cdot \mathrm{min}^{-1}$ for the intermediate insulin dose and $6.8 \pm 0.7 \mathrm{vs} 10.5 \pm 0.8 \mathrm{mg} \cdot \mathrm{kg}^{-1} \cdot \mathrm{min}^{-1}$ for the highest insulin dose used (Protocol 2 vs Protocol 1, $p<0.001$ each).

After $84 \mathrm{~h}$ of fasting the rate of appearance $(\mathrm{Ra})$ and disappearance $(\mathrm{Rd})$ of plasma glucose averaged $1.50 \pm 0.15$ and $1.56 \pm 0.15 \mathrm{mg} \cdot \mathrm{kg}^{-1} \cdot \mathrm{min}^{-1}$, respectively (Table 4). Insulin infusions resulted in significant changes in plasma-specific activities of $\left[{ }^{3} \mathrm{H}\right]$ glucose in both protocols, all of which attained new steady-state conditions during the last 30 min of each infusion period (Fig. 2); hence, the values in the last 30 min of each insulin infusion period were used to calculate total glucose $\mathrm{Ra}$ and $\mathrm{Rd}$ and the values are shown in Table 3.

In Protocol 1, in the absence of exogenous infusions of L-amino acids, hyperinsulinaemia and euglycaemia resulted in dose-dependent increases in the rate of totalbody glucose utilization $(\mathrm{Rd})$, which averaged $22 \%$ above basal at the lowest insulin dose used, three-fold basal at the intermediate dose and seven-fold basal at the highest insulin dose used (Fig. 3). At the highest insulin dose, total glucose Rd was equivalent to the rate of exogenous glucose infused to maintain euglycaemia. Simultaneously, in Protocol 1 there was also a progressive dose-dependent decline in the rate of hepatic glucose production (endogenous glucose $\mathrm{Ra}$ ) averaging $52 \%, 62 \%$ and $100 \%$, respectively (Fig.3). Five out of seven subjects exhibited negative values for endogenous glucose $\mathrm{Ra}$, which is consistent with recent findings by several investigators [2426]. However, the overall mean ( \pm SEM) at the highest insulin dose did not differ from zero $(-0.15 \pm$ $\left.1.19 \mathrm{mg} \cdot \mathrm{kg}^{-1} \cdot \mathrm{min}^{-1}\right)$.

In Protocol 2, the rate of glucose utilization (total $\mathrm{Rd}$ ), determined isotopically, increased progressively with the escalating insulin doses used. At the lowest insulin dose, however, total Rd did not differ from the rate seen in Protocol 1; however, with the intermediate and highest insulin doses the rates of whole-body glucose utilization were $22 \%$ and $23 \%$ lower $(p<0.01)$, respectively. At the same time, the rates of endogenous glucose production did not differ from basal at each insulin dose used and these rates were consistently higher in Protocol 2 than in Protocol 1.

\section{Forearm glucose balance}

After an $84 \mathrm{~h}$ fast, the arteriovenous differences for glucose tended to be slightly positive, but these were not significantly greater than zero (Table 4). At the two highest insulin doses, the arteriovenous differences were increased by four- and seven-fold, respectively. The infusion of amino acids during these same respective insulin doses blunted this increased uptake of glucose by $83 \%$ and $50 \%$. Forearm plasma flow increased with the highest insulin dose only; however, this was not different between protocols. Therefore, net glucose uptake by the forearm muscle tissues was also blunted by amino acid infusion at 
a.

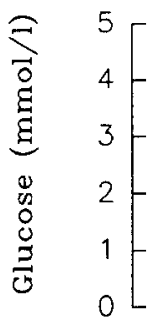

호호조호

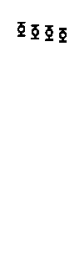

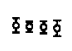

호호 짐

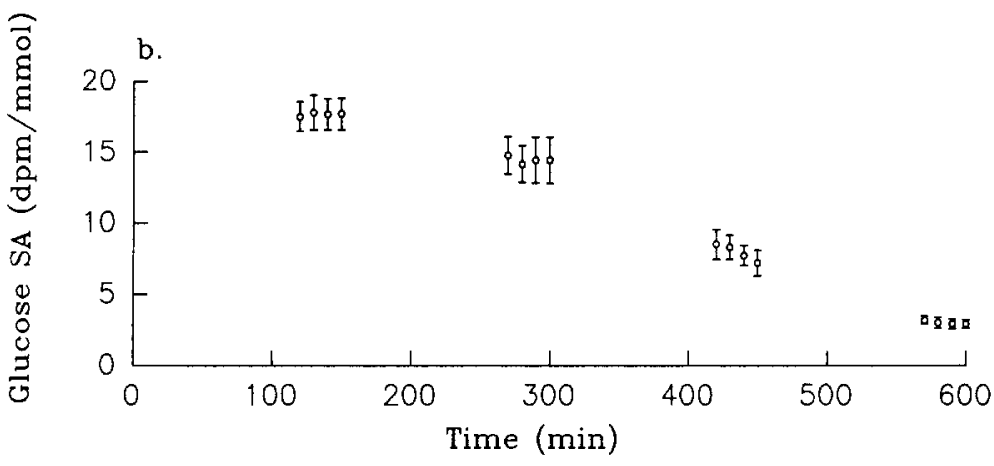

Fig.2a,b. Arterial glucose concentrations (a) and specific activities (SA) (b) during the last 30 min of each basal and experimental period. Values are expressed as means \pm SEM for all studies

the two highest doses of insulin by $71 \%$ and $46 \%$, respectively.

\section{Energy expenditure and substrate oxidation}

Fasting for $84 \mathrm{~h}$ resulted in an average weight loss of $4.0 \pm 0.3 \mathrm{~kg}(81.4 \pm 1.9$ to $77.4 \pm 2.0 \mathrm{~kg})$. The changes in energy expenditure seen with hyperinsulinaemia and euglycaemia were highly dependent on the availability of amino acids (Table 5). In the absence of amino acid infusions (Protocol 1), the metabolic rate increased only with the highest insulin infusion (10\% increase above basal, $p<0.05$ ) which was accompanied by an increase in $\mathrm{RQ}$ from $0.73 \pm 0.01$ to $0.90 \pm 0.02(p<0.01)$. The rise in the rate of energy expenditure was greater $(p<0.05)$ when amino acids were infused at both the intermediate $(7 \%$ above basal) and high ( $27 \%$ above basal) insulin doses. Additionally, the magnitude of the rise in RQ with the highest insulin dose was blunted in Protocol 2 compared to Protocol $1(p<0.01)$.

The changes in energy expenditure were associated with alterations in the individual rates of substrate oxidation (Table 6). Hyperinsulinaemia without the infusion of amino acids resulted in a progressive marked increase in carbohydrate oxidation and a progressive decrease in lipid oxidation with relatively little change in amino acid oxidation. However, simultaneous infusions of amino acids did not increase carbohydrate oxidation nor decrease lipid oxidation as dramatically, but the rate of amino acid oxidation was greater at each insulin dose infused $(p<0.05)$. As a result the proportion of energy derived from amino acid oxidation remained stable during the three insulin doses $(19 \pm 0.4 \%, 20 \pm 0.6 \%$ and $21 \pm 0.5 \%$ ) in Protocol 1 but increased progressively
$(22 \pm 0.5 \%, 26 \pm 0.8 \%$ and $31 \pm 0.6 \%)$ in Protocol 2. On the other hand, the proportion of energy derived from lipid oxidation decreased with escalating insulin doses; while there was a tendency for these rates to be higher in the amino acid infused group, these differences did not achieve statistical significance. The proportion of energy derived from carbohydrate oxidation, in the absence of an exogenous supply of amino acids, increased with progressive insulin infusions. However, the infusion of amino acids blunted this rise, such that at the lowest and intermediate insulin doses used, the rates of carbohydrate oxidation, expressed as percent of total energy expenditure, were not different from zero. At the intermediate insulin

Table 4. Effect of hyperinsulinaemia, euglycaemia and infusions of amino acids on glucose uptake by the forearm

\begin{tabular}{lclc}
\hline $\begin{array}{l}\text { Rate of } \\
\text { insulin infused } \\
\mathrm{mU} \cdot \mathrm{kg}^{-1} \\
\cdot \mathrm{min}^{-1}\end{array}$ & $\begin{array}{l}\text { Glucose } \\
\text { arteriovenous } \\
\text { difference } \\
\mu \mathrm{mol} / \mathrm{l}\end{array}$ & $\begin{array}{l}\text { Plasma } \\
\text { flow } \\
\mathrm{ml} \cdot 100 \mathrm{mg}^{-1} \\
\mathrm{~min}^{-1}\end{array}$ & $\begin{array}{l}\text { Forearm muscle } \\
\text { glucose uptake } \\
\mathrm{nmol} \cdot 100 \mathrm{mg}^{-1} \\
\cdot \mathrm{min}^{-1}\end{array}$ \\
\hline$-\mathrm{AA}$ & & & \\
Basal & $61 \pm 28$ & $2.3 \pm 0.2$ & $138 \pm 105$ \\
0.15 & $39 \pm 44$ & $2.3 \pm 0.2$ & $100 \pm 111$ \\
1.2 & $235 \pm 72^{\mathrm{a}}$ & $2.3 \pm 0.7$ & $696 \pm 209^{\mathrm{a}}$ \\
10.0 & $380 \pm 95^{\mathrm{a}}$ & $3.6 \pm 0.2^{\mathrm{a}}$ & $1414 \pm 408^{\mathrm{a}}$ \\
$+\mathrm{AA}$ & & & \\
Basal & $11 \pm 28$ & $2.1 \pm 0.3$ & $11 \pm 62$ \\
0.15 & $5 \pm 22$ & $3.0 \pm 0.5$ & $10 \pm 56$ \\
1.2 & $39 \pm 39^{\mathrm{b}}$ & $3.0 \pm 0.8$ & $200 \pm 101^{\mathrm{ab}}$ \\
10.0 & $190 \pm 50^{\mathrm{ab}}$ & $3.6 \pm 0.4^{\mathrm{a}}$ & $760 \pm 165^{\mathrm{ab}}$
\end{tabular}

${ }^{a}$ denotes significance from basal within the same protocol $(p<0.05) .{ }^{\mathrm{b}}$ denotes significance from corresponding period in Protocol $1(p<0.05)$. - AA designates Protocol 1 in which amino acids were allowed to fall. + AA designates Protocol 2 in which amino acids were infused 

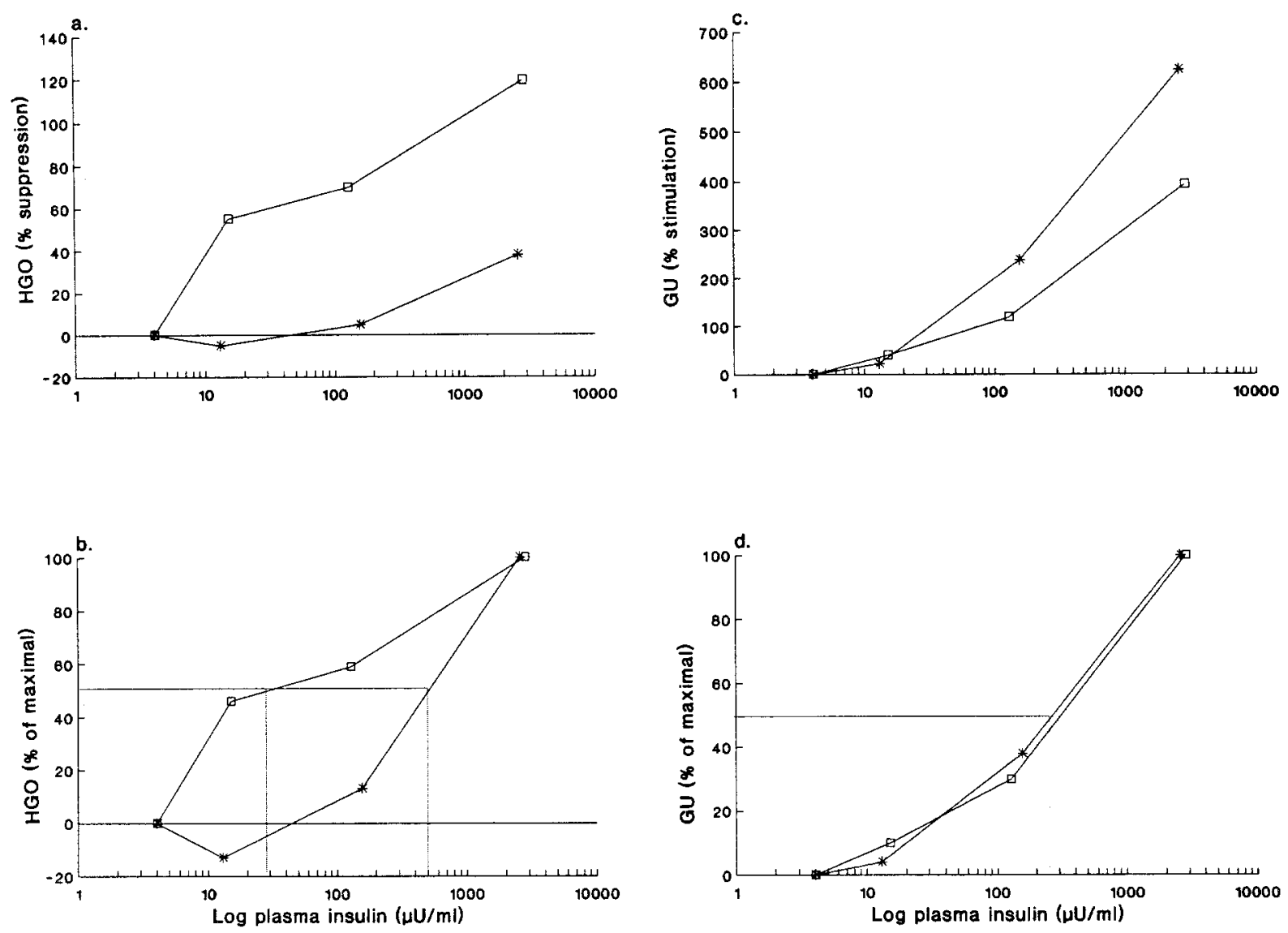

Fig.3a-d. Suppression of endogenous glucose production (HGO), expressed as a percent of basal (a) or as a percent of the maximal suppression (b) and the stimulation of glucose utilization (GU), expressed as a percent of basal (c) or as a percent of the maximal stimulation (d) against log plasma insulin when amino acids were allowed to fall (amino acids, $\square$ ) and when amino acids were infused

( + amino acids, ${ }^{*}$ ). Values in panels $\mathbf{a}$ and $\mathbf{c}$ are expressed as percent suppression from the basal period. Values in panels $\mathbf{b}$ and $\mathbf{d}$ are expressed as percent of maximal suppression within each protocol. Maximal suppression in each protocol was assigned the value of $100 \%$ and the remainder of the values are plotted as a percent of this value

dose, this proportion was lower in Protocol 2 compared to Protocol $1(p<0.05)$. At the highest insulin dose, this proportion increased but was still significantly lower in Protocol $2(27 \pm 16 \%)$ than in Protocol $1(62 \pm 6 \% ; p<0.01)$.

Indirect estimates of glucose storage were made by subtracting the rate of carbohydrate oxidation derived by indirect calorimetry from the total rate of glucose utilization derived by isotope dilution technology. These data indicate that glucose storage increased with increasing insulin doses similarly among the two protocols at basal and the two lowest insulin doses $\left(1.9,2.0\right.$ and $3.8 \mathrm{mg} \cdot \mathrm{kg}^{-1} \cdot \mathrm{min}^{-1}$, respectively). However, during the highest insulin dose used, the infusion of amino acids resulted in a $30 \%$ fall in the rate of carbohydrate storage (from $6.9 \mathrm{mg} \cdot \mathrm{kg}^{-1} \cdot \mathrm{min}^{-1}$ in Protocol 1 to $4.8 \mathrm{mg} \cdot \mathrm{kg}^{-1} \cdot \mathrm{min}^{-1}$ in Protocol 2).

\section{Discussion}

The data from the present study indicate that the infusion of amino acids significantly altered insulin-mediated glucose metabolism in human male volunteers who had fasted for $84 \mathrm{~h}$. This effect appears to be exerted on the rate of hepatic glucose production as well as on the rate of total body glucose utilization, carbohydrate oxidation and carbohydrate storage.

In the absence of amino acid infusions, hyperinsulinaemia and euglycaemia resulted in a dose-dependent decrease in hepatic glucose production, similar to previously published data [31]. On the other hand, the infusion of amino acids altered the suppressive effect of insulin on hepatic glucose production. Elevations of plasma insulin levels up to 35-fold basal did not suppress the rate of hepatic glucose production, while at an approximately 650 fold basal level the suppression of hepatic glucose production was only $50 \%$. When the percent suppression of hepatic glucose production is plotted against the log insulin concentration or as a percent of maximal insulin suppression, it is obvious that amino acid infusions decreased the maximal response of hepatic glucose production to insulin (from $119 \%$ to $38 \%$ suppression) and caused a rightward shift in the insulin-dose response curve such that $\mathrm{ED}_{50}$ increased by approximately 17 -fold (from 29 to $500 \mu \mathrm{U} / \mathrm{ml}$ ). Therefore, these data demonstrate that amino acid availability decreases both the sensitivity and responsiveness to insulin action on hepatic glucose production, suggesting that this effect is directed both at receptor and post-receptor events.

The exact mechanism for the apparent failure of insulin to suppress hepatic glucose production is not well identified, but is, in most part, attributed to enhanced rates of 
Table 5. Effect of hyperinsulinaemia, euglycaemia and infusions of amino acids on total energy expenditure and respiratory quotients

\begin{tabular}{lcl}
\hline $\begin{array}{l}\text { Rate of insulin infused } \\
\mathrm{mU} \cdot \mathrm{kg}^{-1} \cdot \mathrm{min}^{-1}\end{array}$ & $\begin{array}{l}\text { Rate of energy } \\
\text { expenditure } \mathrm{kcal} / \mathrm{h}\end{array}$ & $\begin{array}{l}\text { Respiratory } \\
\text { quotients }\end{array}$ \\
\hline - AA & $76.0 \pm 2.1$ & $0.73 \pm 0.01$ \\
Basal & $74.1 \pm 1.6$ & $0.73 \pm 0.05$ \\
0.15 & $73.9 \pm 2.3$ & $0.79 \pm 0.02^{\mathrm{a}}$ \\
1.2 & $83.5 \pm 2.5^{\mathrm{a}}$ & $0.90 \pm 0.02^{\mathrm{a}}$ \\
10.0 & & \\
+ AA & $81.1 \pm 2.3$ & $0.72 \pm 0.03$ \\
Basal & $80.5 \pm 2.2$ & $0.73 \pm 0.05$ \\
0.15 & $87.0 \pm 4.2^{\mathrm{b}}$ & $0.73 \pm 0.05$ \\
1.2 & $103.8 \pm 3.2^{\mathrm{a}, \mathrm{b}}$ & $0.83 \pm 0.03^{\mathrm{a}, \mathrm{b}}$ \\
\hline
\end{tabular}

a denotes significance from basal within the same protocol $(p<0.05) .{ }^{\mathrm{b}}$ denotes significance from corresponding period in protocol $1(p<0.05)$. - AA designates protocol 1 in which plasma amino acids were allowed to fall. + AA designates protocol 2 in which amino acids were infused

gluconeogenesis in Protocol 2. This is in agreement with studies suggesting that peripheral effects of insulin are responsible for suppression of hepatic glucose production by restricting gluconeogenic substrate availability [3233]. The gluconeogenic process would be facilitated by the increased circulating plasma glucagon levels [34-36] and by the increased availability of gluconeogenic amino acids, particularly alanine and glycine, to the liver. Unfortunately, most of the amino acid solutions currently available for clinical use in the United States have an inappropriately high content of these two amino acids which are used as "nitrogen fillers". Assuming maximal conversion of all the gluconeogenic amino acids infused to glucose, we can estimate that the theoretical maximal amount of glucose [37] that could be produced would be $0.6,2.0$, and $2.5 \mathrm{mg} \cdot \mathrm{kg}^{-1} \cdot \mathrm{min}^{-1}$, respectively, at the three insulin dosages used. These amounts would be sufficient to account for the increases in hepatic glucose production observed with amino acid infusions, especially at the intermediate and high doses of insulin used.

The present study shows that the availability of amino acids caused significant alterations in overall glucose and carbohydrate utilization. Specifically, amino acids blunted the insulin-stimulated increases in whole-body rates of glucose utilization, particularly at the intermediate and highest insulin doses, and by a similar decrease in net glucose uptake by the forearm tissues. When the isotopicallyderived glucose disposal data were subjected to nonlinear regression analysis, the calculated maximal rate of glucose utilization in Protocol 2 was $21 \%$ lower than that observed in Protocol $1\left(8.5 \pm 1.2\right.$ vs $10.7 \pm 0.4 \mathrm{mg} \cdot \mathrm{kg}^{-1}$. $\min ^{-1}$ ) with no change in the calculated " $\mathrm{ED}_{50}$ ". These data indicate that the exogenous infusion of an L-amino acid solution, in quantities sufficient to maintain the levels of the branched chain amino acids near $84 \mathrm{~h}$ fasted basal levels, resulted in a state of insulin resistance to glucose utilization. This resistance was primarily due to decreased tissue responsiveness to insulin, which is thought to be related to impaired post-receptor activity [38-40]. The findings of the present study are in many respects similar to data previously obtained by us [13] and by Pisters et al. [41], in overnight fasted volunteers, who also noted decreased total-body glucose $\mathrm{Rd}$ in conjunction with decreased glucose uptake across forearm tissues at an insulin infusion rate identical to the intermediate dose used in the present study.

The data derived from indirect calorimetry indicate that both the absolute rate of carbohydrate oxidation as well as the percent of total energy accounted for by carbohydrate oxidation were lower when amino acids were infused. When the data derived by indirect calorimetry are combined with those derived isotopically, it becomes clear that the availability of amino acids resulted in decreased oxidation as well as decreased storage of glucose, indicating that the defect is exerted on both glycogen deposition as well as on the rate of glycolysis. While the exact mechanism of these changes remains unclear, it can be speculated that the splanchnic tissues would play only a minor role as it is well established that in the post-absorptive period, glucose utilization by the liver accounts for only $15-20 \%$ of whole body rate of glucose utilization $[34,35$, 42]. Therefore, the major effect of amino acids would appear to be exerted on skeletal muscle. Furthermore, it could be envisioned that a likely site of action of amino acids on skeletal muscle would be at the glucose transport step. With the recent information regarding the nature of the insulin-mediated glucose transporter, GLUT-4, and its regulation in muscle, it can be speculated that the effect of amino acid availability would be short-term and exerted at decreasing the rate of translocation of receptors from the intracellular stores to the plasma membrane. An opposite effect was recently proposed by Klip et al. for changes observed in glucose transport and exercise [43]. Additional data has been published that suggests that amino acids may play an important role in modulating insulin action on glucose transport in the adipocyte $[44,45]$. These findings, however, do not preclude an effect of amino acids on more distal metabolic sites.

Table 6. Rates of carbohydrate, amino acid and lipid oxidation as determined by indirect calorimetry

\begin{tabular}{llll}
\hline $\begin{array}{l}\text { Rate of insulin } \\
\text { infused } \\
\mathrm{mU} \cdot \mathrm{kg}^{-1} \\
\cdot \mathrm{min}^{-1}\end{array}$ & $\begin{array}{l}\text { Carbohydrate } \\
\text { oxidation } \\
\mathrm{mg} \cdot \mathrm{kg}^{-1} \\
\mathrm{~min}^{-1}\end{array}$ & $\begin{array}{l}\text { Amino acid } \\
\text { oxidation } \\
\mathrm{mg} \cdot \mathrm{kg}^{-1} \\
\cdot \mathrm{min}^{-1}\end{array}$ & $\begin{array}{l}\text { Lipid } \\
\text { oxidation } \\
\mathrm{mg} \cdot \mathrm{kg}^{-1} \\
\cdot \mathrm{min}^{-1}\end{array}$ \\
\hline$-\mathrm{AA}$ & & & \\
Basal & $-0.33 \pm 0.10$ & $1.16 \pm 0.04$ & $1.90 \pm 0.11$ \\
0.15 & $0.02 \pm 0.34$ & $0.92 \pm 0.03^{\mathrm{a}}$ & $1.71 \pm 0.16$ \\
1.2 & $1.05 \pm 0.39^{\mathrm{a}}$ & $0.97 \pm 0.03^{\mathrm{a}}$ & $1.26 \pm 0.17^{\mathrm{a}}$ \\
10.0 & $3.51 \pm 0.38^{\mathrm{a}}$ & $1.18 \pm 0.04$ & $0.41 \pm 0.16^{\mathrm{a}}$ \\
$+\mathrm{AA}$ & & & \\
Basal & $-0.56 \pm 0.23$ & $1.18 \pm 0.04$ & $2.11 \pm 0.25$ \\
0.15 & $-0.23 \pm 0.74$ & $1.17 \pm 0.04^{\mathrm{b}}$ & $2.00 \pm 0.32$ \\
1.2 & $-0.27 \pm 0.80^{\mathrm{b}}$ & $1.58 \pm 0.06^{\mathrm{a}, \mathrm{b}}$ & $2.12 \pm 0.29^{\mathrm{b}}$ \\
10.0 & $3.00 \pm 1.40$ & $2.44 \pm 0.09^{\mathrm{a}, \mathrm{b}}$ & $1.11 \pm 0.60^{\mathrm{a}}$ \\
\hline
\end{tabular}

The values represent mean \pm SEM of indirect calorimetry measurements taken during a $30 \mathrm{~min}$ basal period or the last $30 \mathrm{~min}$ of each insulin infusion period. a denotes significance from basal within the same Protocol $(p<0.05)$. ${ }^{\mathrm{b}}$ denotes significance from corresponding period in Protocol $1(p<0.05)$. - AA designates Protocol 1 in which plasma amino acids were allowed to fall. + AA designates Protocol 2 in which amino acids were infused 
Consistent with the findings in the present study, several in vitro and in vivo studies have established a possible role for amino acids, and particularly the branched chain amino acids, in decreasing glucose utilization in skeletal muscle [46-52]. Studies by Chang and Goldberg [48] demonstrated that leucine was capable of inhibiting glucose and pyruvate oxidation by approximately $30 \%$ in muscle tissue preparations taken from 3-day fasted rats. Further studies have established that this effect may be mediated by the availability of $\alpha$-ketoisocaproate, the ketoacid of leucine $[51,53]$. Studies from this laboratory in overnight fasted volunteers have confirmed that the infusions of either leucine [50] or $\alpha$-ketoisocaproate [51] resulted in decreased glucose utilization by forearm muscle tissues and further suggested that this decrease in the rate of glucose utilization must have been due to a decrease in the rate of glucose oxidation and to an additional inhibitory effect on glycogen formation in skeletal muscle. While Schwenk et al. [52] have extended these findings to isoleucine and threonine, the effects of other individual amino acids on glucose oxidation and storage in muscle are less well defined. The findings of the present study are reminiscent of the Randle effect for the influence of non-esterified fatty acids on decreasing glucose oxidation in rat [54] and human [1] skeletal muscle. It is clear, however, that the amino acid-induced changes in glucose utilization were not related to the levels of plasma non-esterified fatty acids as these were not different in the two protocols.

The results from the present study, and those derived from previous studies in overnight fasted volunteers [13, 41], appear to contradict conclusions made by Boden and Tappen [55], which indicate that hyperaminoacidaemia did not alter insulin-stimulated glucose utilization in overnight fasted human volunteers. In the study of Boden and Tappen the infusion of amino acids, in the context of hyperinsulinaemia $(50-150 \mu \mathrm{U} / \mathrm{ml})$ resulted in a $45 \%$ suppression in the amount of exogenous glucose required to maintain euglycaemia (from $2.8 \pm 0.4$ to $1.6 \pm 0.6 \mathrm{mg}$. $\left.\mathrm{kg}^{-1} \cdot \min ^{-1}\right)$. However, only $70 \%$ of this decrease in infused exogenous glucose could be accounted for by the amino acid-induced increase in hepatic glucose production. Additionally, in the study of Boden and Tappen, the infusion of amino acids (plus insulin) resulted in a greater than two-fold increase in circulating plasma insulin over those attained in the insulin plus saline infusions (without amino acids). Therefore, any insulin resistance to glucose utilization may have been masked by the increased insulin concentrations.

In conclusion, the present study suggests that the availability of amino acids to human volunteers who have fasted for $84 \mathrm{~h}$, in amounts sufficient to match the plasma levels of the branched chain and several other essential amino acids, caused significant alterations in insulinmediated glucose and carbohydrate homeostasis. Specifically, amino acid infusions resulted in decreased rates of insulin-mediated glucose utilization and blunted insulinmediated decreases in glucose production. These findings have significant clinical bearing on the aetiology of insulin resistance seen with trauma, diabetes and fasting, conditions known to be associated with increased levels of amino acids.
Acknowledgements. The technical assistance of Ms. T. Uselton and Ms. M. Kahler is appreciated. This work was supported by National Institutes of Health Grants DK-20593, DK-26657, RR-00095, DK42562 and DK-43290.

\section{References}

1. Ferrannini E, Barrett EJ, Bevilacqua S, DeFronzo RA (1983) Effect of fatty acids on glucose production and utilization in man. J Clin Invest 72: 1737-1747

2. Rizza R, Mandarino L, Gerich J (1982) Cortisol-induced insulin resistance in man: impaired suppression of glucose utilization due to a post-receptor defect of insulin action. J Clin Endocrinol Metab 54: 131-138

3. Baron A, Wallace P, Olefsky J (1987) In vivo regulation of noninsulin-mediated glucose uptake by epinephrine. J Clin Endocrinol Metab 64: 889-895

4. Orskov L, Schmitz O, Jorgensen J et al. (1989) Influence of growth hormone on glucose-induced glucose uptake in normal men as assessed by the hyperglycemic clamp technique. J Clin Endocrinol Metab 68: 276-282

5. Del Prato S, Castellino P, Simonson DC, DeFronzo RA (1987) Hyperglucagonemia and insulin-mediated glucose metabolism. J Clin Invest 79: 547-556

6. Kettlehut IC, Foss MC, Migliorini RH (1980) Glucose homeostasis in a carnivorous animal (cat) and in rats fed a high-protein diet. Am J Physiol 239: R437-R444

7. Peret J, Foustock S, Chanez M, Bois-Joyeux B, Assan R (1981) Plasma glucagon and insulin concentrations and hepatic phosphoenolpyruvate carboxykinase and pyruvate kinase activities during and upon adaptation of rats to a high protein diet. J Nutr 111: 1175-1184

8. Rosetti L, Rothman DL, DeFronzo RA, Shulman GI (1989) Effect of dietary protein on in vivo insulin action and liver glycogen repletion. Am J Physiol 257: E212-E219

9. Gannon MC, Nuttal FQ (1987) Acute effects of ingestion of carbohydrate, protein, or fat on cardiac glycogen metabolism in rats. Metabolism 36:595 600

10. Mak RJ, Turner C, Thompson T, Haycock G, Chantler C (1986) The effect of a low protein diet with amino acid/keto acid supplements on glucose metabolism in children with uremia. J Clin Endocrinol Metab 63: 985-989

11. Snyder D, Pulido LB, Kagan A (1968) Dietary reversal of the carbohydrate intolerance in uremia. Proc EDTA 5: 205

12. Sweeney JS (1927) Dietary factors that influence the dextrose tolerance test. Arch Int Med 40: 818-830

13. Flakoll PJ, Kulaylat M, Frexes-Steed M, Hill JO, Abumrad NN (1991) Amino acids enhance insulin resistance to glucose disposal in overnight fasted humans. J Parent Enter Nutr 15: 123127

14. Tessari P, Inchiostro S, Biolo G et al. (1985) Hyperaminoacidaemia reduces insulin-mediated glucose disposal in healthy man. Diabetologia 28: 870-872

15. Brown LL, Williams PE, Becker TA, Ensley RJ, May MM, Abumrad NN (1988) Rapid high-performance liquid chromatographic method to measure plasma leucine: importance in the study of leucine kinetics in vivo. J Chromatog 426:370-375

16. Livesey G, Elia M (1988) Estimation of energy expenditure, net carbohydrate utilization, and net fat oxidation and synthesis by indirect calorimetry evaluation of errors with special reference to the detailed composition of foods. Am J Clin Nutr 47: 608628

17. Frexes-Steed M, Warner ML, Bulus N, Flakoll P, Abumrad NN (1990) Role of insulin and branched-chain amino acids in regulating protein metabolism during fasting. Am J Physiol 258: E907-E917

18. Abumrad NN, Rabin D, Diamond M, Lacy WW (1981) Use of a heated superficial hand vein as an alternative site for the measurement of amino acid concentrations and for the study of glucose and alanine kinetics in man. Metab 30: 936-940 
19. Clarke RSJ, Hellon RF (1957) Venous collection in forearm and hand measured by strain gauge and volume plethysmographs. Clin Sci 16: 103-117

20. Schwenk WF, Butler PC, Haymond MW, Rizza RA (1990) Underestimation of glucose turnover corrected with high performance liquid chromatography purification of $\left[6-{ }^{3} \mathrm{H}\right] \mathrm{glucose}$. Am J Physiol 258: E228-E233

21. DeFronzo RA, Tobin JD, Andres R (1979) Glucose clamp technique: a method for quantifying insulin secretion and resistance. Am J Physiol 237: E214-E223

22. Heinrikson RL, Meredith SC (1984) Amino acid analysis by reverse-phase HPLC: pre-column derivatization with phenylisothiocyanate. Anal Biochem 136: 65-74

23. Wide L, Porath J (1966) Radioimmunoassay of protein with use of Sephadexcoupled antibodies. Biochim Biophys Acta 130: $255-260$

24. Aguilar-Parada E, Eisentraut AM, Unger RM (1969) Pancreatic glucagon secretion in normal and diabetic subjects. Am J Med Sci 257: 415-419

25. DeBodo RD, Steele R, Altszuler N, Dunn A, Bishop JS (1963) On the hormonal regulation of carbohydrate metabolism: studies with $\left[{ }^{14} \mathrm{C}\right]$ glucose. Rec Prog Horm Res 19: 445-448

26. Bell PM, Firth RG, Rizza RA (1986) Assessment of insulin action in insulin-dependent diabetes mellitus using $6-{ }^{14} \mathrm{C}$-glucose, 3- ${ }^{3} \mathrm{H}$-glucose, and $2{ }^{3} \mathrm{H}$-glucose: differences in the apparent pattern of insulin resistance depending on the isotope used. J Clin Invest $78: 1479-1486$

27. Finegood DT, Bergman RN, Vranic M (1988) Modelling error and apparent isotope discrimination confound estimation of endogenous glucose production during euglycemic glucose clamps. Diabetes 37: 1025-1034

28. McMahon M, Schwenk W, Haymond MW, Rizza RA (1989) Underestimation of glucose turnover measured with $6{ }^{3} \mathrm{H}$ - and $6,6^{2} \mathrm{H}_{2}$ - but not $6{ }^{-14} \mathrm{C}$-glucose during hyperinsulinemia in humans. Diabetes 38: 97-105

29. Garlick PJ, McNurlan MH, McHardy KC et al. (1987) Rates of nutrient utilization in man measured by combined respiratory gas analysis and stable isotopic labelling: effect of food intake. Human Nutr Clin Nutr 41: 177-191

30. Snedecor GW, Cochran WG (1967) Statistical methods. Iowa State University Press, Ames

31. Rizza R, Mandarino L, Gerich J (1981) Dose-response characteristics for effects of insulin on production and utilization of glucose in man. Am J Physiol 240: E630-E639

32. Ader M, Bergman RN (1990) Peripheral effects of insulin dominate suppression of fasting hepatic glucose production. Am $\mathbf{J}$ Physiol 258: E1020-E1032

33. Prager R, Wallace P, Olefsky JM (1987) Direct and indirect effects of insulin to inhibit hepatic glucose output in obese subjects. Diabetes 36: 607-611

34. Cherrington AD, Steiner KE, Williams PE, Lacy WW (1981) Consequences of physiologic changes in the plasma glucagon concentration. In: Cobelli C, Bergman RN (eds) Carbohydrate metabolism 2nd edn. John Wiley \& Sons, Chichester New York Brisbane Toronto, pp 153-168

35. Myers SR, Diamond MP, Adkins-Marshall BA, Williams PE, Stinsen R, Cherrington AD (1991) Effects of small changes in glucagon on glucose production during a euglycemic, hyperinsulinemic clamp. Metab 40: 66-71

36. Shulman GI, Liljenquist JE, Williams PE, Lacy WW, Cherrington AD (1979) Glucose disposal during insulinopenia in somatostatin-treated dogs. J Clin Invest 62: 487-491

37. Chiasson JL, Liljenquist JE, Shulman GI, Jennings AS, Keller U, Cherrington AD (1979) Gluconeogenesis: methodological approaches in vivo. Fed Proc 36: 230-235
38. Kahn C (1978) Insulin resistance, insulin insensitivity, and insulin unresponsiveness: a necessary distinction. Metab 48: 836-842

39. Olefsky $\mathbf{J}$ (1981) Insulin resistance and insulin action: an in vitro and in vivo perspective. Diabetes $30: 148-162$

40. Kolterman OG, Insel J, Saekow M, Olefsky JM (1980) Mechanism of insulin resistance in human obesity - evidence for receptor and post-receptor defects. J Clin Invest 65: 1273-1284

41. Pisters PWT, Restifo NP, Cersosimo E, Brennan MF (1991) The effects of englycemic hyperinsulinemia and amino acid infusion on regional and whole body glucose disposal in man. Metab 40: $59-65$

42. DeFronzo RA, Jacot E, Jequier E, Maeder E, Wahren J, Felber JP (1981) The effect of insulin on the disposal of intravenous glucose. Results from indirect calorimetry and hepatic and femoral venous catheterization. Diabetes 30: 1000-1007

43. Klip A, Paquet MR (1990) Glucose transport and glucose transporters in muscle and their metabolic regulation. Diab Care 13: 228-243

44. Marshall S, Monzon R (1989) Amino acid regulation of insulin action in isolated adipocytes: selective ability of amino acids to enhance both insulin sensitivity and maximal insulin responsiveness of the protein synthesis system. J Biol Chem 264: 2037-2042

45. Traxinger RR, Marshall S (1989) Role of amino acids in modulating glucose-induced desensitization of the glucose transport system. J Biol Chem 264: 20910-20916

46. Goldberg A, Odessey R (1974) Oxidation of amino acids by diaphragms from fed and fasted rats. Am J Physiol 223: 1384-1391

47. Buse M, Biggers F, Friderici K, Buse J (1972) Oxidation of branched-chain amino acids by isolated hearts and diaphragms of the rat. J Biol Chem 247: 8085-8096

48. Chang T, Goldberg A (1978) Leucine inhibits oxidation of glucose and pyruvate in skeletal muscle during fasting. J Biol Chem 253:3696-3701

49. Abumrad N, Rabin D, Wise K, Lacy W (1982) The disposal of an intravenously administered amino acid load across the human forearm. Metab 31:463-470

50. Abumrad N, Robinson R, Gooch B, Lacy W (1982) The effect of leucine infusion on substrate flux across the human forearm. J Surg Res 32: 453-463

51. Buckspan R, Hoxworth B, Cersosimo E et al. (1986) Alphaketoisocaproate is superior to leucine in sparing glucose utilization in humans. Am J Physiol 251: E648-E653

52. Schwenk F, Haymond M (1987) Decreased uptake of glucose by human forearm during infusion of leucine, isoleucine or threonine. Diabetes 36: 199-204

53. Tischler ME, Goldberg AL (1980) Amino acid regulation and effect of leucine on pyruvate oxidation in rat atrial muscle. Am J Physiol 238-E480-E487

54. Randle PJ, Newsholme EA, Garland PB (1964) Regulation of glucose uptake by muscle. 8 . Effects of fatty acids, ketone bodies and pyruvate, and of alloxan-diabetes and starvation on the uptake and metabolic fate of glucose in rat heart and diaphragm muscles. Biochem J 93: 652-665

55. Boden G, Tappy L (1990) Effects of amino acids on glucose disposal. Diabetes 39: 1079-1084

Received: 20 August 1991

and in revised form: 26 November 1991

Dr. P.J.Flakoll

$750 \mathrm{MRB}$

Vanderbilt University Medical Center

Nashville, TN 37232

USA 